\title{
An Economical Approach for User Behaviour Determination for the Selection of Type of Location Based Services
}

\author{
Udaya Dampage and Dileeka Dias
}

\begin{abstract}
The vision of this research paper is that the mobile phone is aware of its user's motion state and surroundings and modifies its behaviour especially the characteristics of Location-Based-Services based on this information. In the research it is implemented, and evaluated a methodology which can identify individual user. states. This learning is expected to occur online and not expected the requirement of any external supervision. The proposed system relies on hidden markov modelling and Log Likelihood Method. The implementation of the methodology is performed by first training the hidden markov model for the required number of states by an intended network trace. The log likelihood value of the data for each hidden markov model in the set is computed and the motion state is identified by choosing the hidden markov model that produced the highest value. The results of simulations carried out in WCDMA environment indicate that the proposed method is able to assist to create a meaningful user context model at various propagation conditions defined by both 3rd Generation Partnership Project (3GPP) and Wireless World Initiative New Radio (WINNER) propagation scenarios while only requiring a network trace without having an integrated sensor onboard cellular phone or any other wearable sensor device.
\end{abstract}

Keywords: Location Based Services, Wideband Code Division Multiple Access, hidden markov model, Log Likelihood value.

\section{Introduction}

As predicted in [1] there is a bright future for mobile positioning as the key technology for enabling Location Based Services applications, which themselves will become increasingly important as a key enabler of value added services. There are number of methods proposed for determination of user state of a mobile station, however most are based on assistance of an integrated sensor onboard cellular phone or any other wearable sensor device, that is: those methods require modifications to the all applicable mobile transceivers. In [2] Qualcomm Inc., recognizes one of the key requirements for implementation of Location Base Services, is as handset impactminimization of incremental drain of battery power and impact to the handset by new circuitry or software. Some other systems rely on complex algorithms such as Viterbi, hence slower and more burdens on processing. Qualcomm Inc., further states that network efficiency-utilization of minimum over-the-air and backhaul network bandwidth for individual/continuous position reports [2] another major key requirement for implementation of Location Base Services.
Hence it is felt the requirement of proposing a simpler, faster and comparatively lesser processor intensive method with minimum bandwidth consumption for determination of user state of a mobile station at least up to maximum posted speed limits for vehicles and without getting assistance of an integrated sensor onboard cellular phone or any other wearable sensor device, that is: with less modifications to the all applicable mobile transceivers.

\section{Background}

\subsection{Vision, Objective and Scope}

The vision is that the mobile phone is aware of its user's state and surroundings and modifies its behaviour especially the characteristics of Location-Based-Services based on this information. 
The objective of this research is to propose a simpler, faster and comparatively lesser computationally burdened method for determination of user state of a mobile station up to maximum posted speed limits for vehicles $^{1}$ and without getting assistance of an integrated sensor onboard cellular phone or any other wearable sensor device, that is: with less modifications to the all applicable mobile transceivers to $\mathrm{WCDMA}^{2}$.

In this paper it a relatively economical system which can identify individual user states will be proposed, implemented, and evaluated. This learning is expected to occur online and does not require any external supervision. Proposed method is not intended to be a total solution; however the process based on the proposed method is intended to be a part of an organization of services.

\subsection{Survey of Previous work}

This section summarizes current knowledge and what other authors have done in the various topics within the purview of this research paper.

In [3], it has discussed two different filtering approaches: namely Hidden Markov Model and Kalman filter, in order to minimize the impact due to ambiguity and signal degradation, on position estimates in cellular positioning based on database comparison method. He points out that Hidden Markov Model based methods have fewer parameters and easier to estimate, the estimator seems to be less sensitive to errors in the model parameters and multi hypothesis processing is simpler. He concludes stating that the Hidden Markov Model based approach is more suited to perform position estimation of a database comparison process.

Daniel Siewiorek et al of Interaction Institute and Institute for Complex Engineered Systems, Carnegie Mellon University have presented in [4] on 'SenSay' - a context-aware mobile phone that adapts to dynamically changing environmental and physiological states and also provide the caller with feedback on the current status of the user. A number of sensors including accelerometers, light, and microphones are mounted at various points on the body to provide data about the user's context.

Andreas Krause et al have presented in [5], a design, implementation, and evaluation of a wearable system which can learn contextdependent personal preferences by identifying individual user states and observing how the user interacts with the system in these states.

Ian Anderson and Henk Muller [6] have showed that by using patterns of signal strength fluctuations and changes to the current serving cell and monitoring neibhouring cells in GSM, it is possible to distinguish between various states of movement using Hidden Markov Model compares with the results of method based on Artificial Neural Network. However this paper utilizes a relatively complex Viterbi algorithm to infer most likely state sequence.

\subsection{Overview of this Paper}

Next chapter covers theoretical background, followed by an introduction to the proposed method and simulation methodology respectively at chapters 4 and 5. Chapter 6, presents results and relevant analysis. The paper is concluded with chapter 7 , which covers summary, conclusion and proposed future work.

\section{Theoretical Development}

\subsection{Markov Property}

If we know the present state, then knowing past states gives no added information about the future states. Given the present, the future is conditionally independent of the past.

$\operatorname{Pr}\left(S_{t+1} / S, S_{A-1 .}\right)=\operatorname{Pr}\left(S_{t+1} / S\right)$

where $\overline{5}$ is the set of all states, and $S_{\mathrm{i}}$ is the state variable.

When using Markov models for modelling a physical phenomenon, we generally only have

1. Maximum posted speed limits for vehicles in US highways as of June 2006 is stated in http://www.iihs.org/laws/state_laws/ speed_limit_laws.html.. US Congress repealed the National Maximum Speed Limit in 1995. As of May 2005, 31 US states had raised speed limits to $70 \mathrm{mph}$ or higher on some portion US roadway systems.

2. Wideband Code Division Multiple Access - WCLMA standards were initially developed by European Telecommu nication Standards Institute (ETSI). The WCDMA standard reference is ETSI TS 125211 V3.2.0. 
access to a set of observations $\bar{O}$ for the states, $\overline{5}$ which occur in a hidden Markov model as shown on the next page:

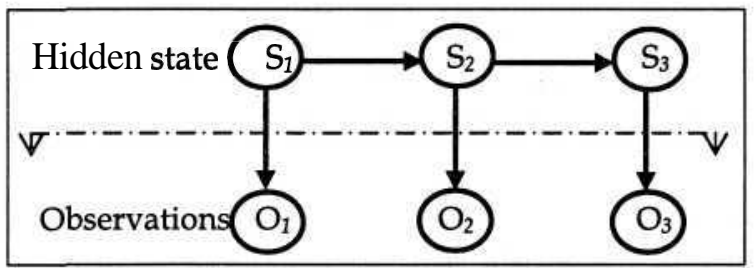

Figure 1: A Hidden Markov Model

In addition to the Markov property between states $S_{\text {: }}$ this model makes a further assumption that the observations are conditionally independent given the current state.

$\operatorname{Pr}\left(O_{i} / \bar{S}, \bar{O}\right)=\operatorname{Pr}\left(O_{i} / S_{i}\right)$

As above this implies that state $S$ captures all relevant information of the system and it further implies that any measurement is independent given the state.

A hidden Markov model encapsulates two separate components, a transition (process) model, and a observation (measurement) model. The transition model describes the relationship between neighbouring states (in time or space) and it is shown graphically between $S$ in the above figure. The observation model describes how these observations are generated from those states and is shown graphically by the vertical links between $5_{i}$ and $O_{i}$ in the above figure.

Estimating the state $S_{i}$ from observation $\bar{O}$, a known observation model is described as an inference or state estimation. Using data to find the transition and observation models are generally called learning or parameter estimation.

\subsection{N-state Hidden Markov Model}

A $N$-State Markov (process) model $\Gamma=(\pi, A, B)$, is defined by the following parameters:

Set of states: $\left(\mathrm{S}_{1}, \mathrm{~S}_{2}, \mathrm{~S}_{3}, \ldots, \mathrm{S}_{\mathrm{N}}\right)$

State at time $/=S_{t}$

Set of state probabilities:

Initial state probability: $\pi(t)=$ Probability of being in state 5 . at time $t$

$=\operatorname{Pr}\left[S_{i}=S_{i}\right]$

$\imath=1,2, \ldots ., N$

Set of state transition probabilities:

Probability of shifting from state 5 . at time $t$ to state 5 , at time $t+1$,

$\mathrm{A}=a_{i j}(t)=\operatorname{Pr}\left[S_{t+1}=S_{j} \mid S_{t}=S_{j}\right]$

$i, j=1,2, \ldots, N$

Set of input-to-outputtransition probabilities for each state:

For data sequence:

$\bar{O}=\left(O_{1}, O_{2}, \ldots . O_{t}, \ldots . O_{T}\right) ;$

$B=b_{i}\left(O_{t i}\right)$

$=\operatorname{Pr}\left[\right.$ data bit $\mathrm{O}_{t}$

$t=1,2, \ldots, \ldots . . T$ occuring $\mid \mathrm{St}=\mathrm{Sj}]$,

The time increment is equal to the bit duration.

\section{Proposed Methodology}

\subsection{Learning of Hidden Markov Model}

In view of improvement of initial model parameters $\Gamma=(\pi, A, B)$, the expectationmaximization (EM) algorithm is utilized. Here the complete log likelihood $\operatorname{Pr}(\bar{O}, \mathrm{~S} \mid \Gamma)$, that a sequence $\bar{O}$, of data bits $O_{t}$ were generated by the hidden markov model is maximized by adjusting the hidden markov model parameters $\Gamma$. Since of incomplete data, because of the states $\overline{5}$ are hidden, the expected complete log likelihood should be maximized, with respect to the parameters $\Gamma$.

$\operatorname{Argmax} \Gamma \sum \operatorname{Pr}(S \mid \bar{Q}, \Gamma) \log \operatorname{Pr}(O, S \backslash \Gamma)$

The maximum likelihood parameters are the improved hidden markov model parameters, and the process consisted of the following steps:

\section{Step 0}

Starting with an initial $\Gamma=(\pi, A, B)$

Step 1

With $\Gamma=(\pi, A, B)$ as the model,

Computation of the forward variables:

$\alpha_{i}(i)=\operatorname{Pr}\left[O_{1}, O_{2}, \ldots . O_{t}, S_{t}=S_{i} / \Gamma\right]$ 
The backward variables:

The backward variables:

$$
\begin{aligned}
& \beta_{t}(i)=\operatorname{Pr}\left[O_{t+1}, O_{t+2}, \ldots, O_{T} / S_{t}=S_{i}, \Gamma\right] \\
& \text { for } t=1,2, \ldots, \mathrm{T} \text { and } t=1,2 \ldots \mathrm{N} \text {. }
\end{aligned}
$$

Step 2

Computation of the state transition probabilities given $O$ and $\Gamma$ and update the parameters $A$, and $B$ according to:

$\gamma_{t}(i)=\operatorname{Pr}\left[S_{t}=S_{i} \mid \bar{O}, \Gamma\right]=\frac{\alpha_{t}(i) \beta_{t}(i)}{\operatorname{Pr}[\bar{O} \mid \Gamma]}$

$i=1,2, \ldots, N$

\section{Step 3}

Going back to step 1 with the new values of

$$
\hat{\mathrm{I}}=(\hat{\pi}, A, B) \text {. }
$$

That is $\hat{\Gamma}=\Gamma$ obtained in step 2 , and repeating until convergence, until such time that the successive values of $\operatorname{Pr}(O \backslash \hat{\Gamma})$ differ by a minute value.

\subsection{Recognition of State}

Once a set of hidden markov models are generated for each state, the identification of new state, from a new sequence of observations $\bar{O}$ can be performed by computing the log likelihood of $\bar{O}$ given for each of the models: $\log$ $\operatorname{Pr}(\bar{O} \mid \hat{\Gamma})$, for each hidden markov model. The model $\Gamma$. that provides the highest value is the model that most likely generated the new sequence $\bar{O}$. In order to calculate $\operatorname{Pr}(\bar{O} \mid \hat{\Gamma})$ we can marginalize out the hidden states from the joint distribution $\operatorname{Pr}(\bar{O}, \bar{S} \mid \hat{\Gamma})$. That is, the likelihood is the sum of the likelihoods of $\bar{O}$ for every possible sequence of states $\overline{5}$ in the model

$\log P(\bar{O} \mid \Gamma)=\sum_{\bar{S}} \log P(\bar{O}, \bar{S} \mid \Gamma)$

The probabilities of observing the sequence $\bar{O}$ up to time step $t$ and ending up in state $S_{t}$ given the model are:

$$
\alpha_{t}(i)=P\left(O_{1}, O_{2}, \ldots O_{t}, S_{t}=S_{i} \mid \Gamma\right)
$$

At each successive time step it is needed only to update a by

$$
a_{t+1}(j)=\left\lfloor\sum_{i} \alpha_{t}(i) a_{i j} b_{j}\left(O_{t+1}\right)\right.
$$

That is sum for $\alpha(i)$ over all possible states $\overline{5}$ multiplied by the transition probabilities of shifting from that end state to the current state $S$, and then multiplying by the probability of observing the current observation $O$. from state 5. The end result will be the likelihood of the data for the particular hidden markov model.

\section{Simulation}

\subsection{Assumptions}

Further following were assumed for the simulation: Firstly that: the base station employs an idealized rake receiver. The rake receiver is idealized in the sense that: the number of taps -in.this.reee.iver.-is.equall to the number of multipath components and the receiver has perfect knowledge of the delay of each multipath component and the rake receiver uses the pilot symbols in the $\mathrm{DPCCH}^{3}$ to estimate the phase offset generated by the channel. Then, the receiver extracts each multipath component and employs an equal gain combiner to generate a test statistic, which is evaluated via a simple zero

-threshold test. Secondly it is assumed that each component of the multipath channel has the same Doppler spread.

\subsection{Simulation of Physical Layer of 3G Wireless System}

The simulation ${ }^{4}$ was performed on a Pentium ${ }^{\mathrm{TM}}$ D CPU 3.40GHz based personal computer with 1024 MB RAM and Matlab ${ }^{\text {TM }}$ R2006a (version 7.2.0.232) was utilized as the simulation platform.

WCDMAsim(TM) was utilized as the simulator of physical layer of $3 \mathrm{G}$ wireless system. The WCDMAsim $^{5}$ is a Matlab $^{\mathrm{TM}}$ based, physical layer simulator of a $3 \mathrm{G}$ wireless system that conforms to the WCDMA standard. This simulator emulates the behavior of WCDMA base and mobile stations in specular multipath fading environments. WCDMAsim provides a technically accurate and detailed emulation of a WCDMA system [7].

3. Dedicated Physical Control Channel.

4. Please contact authors to obtain relevant Matlab codes utilized in simulations, if required.

5. Developed by Mobile and Portable Radio Research Group at Bradley Department of Electrical and Computer Engineering, Virginia Polytechnic Institute and State University, Blacksburg, Virginia. 
During the simulations the uplink simulator emulates the operation of a WCDMA mobile station in a frequency selective, multipath fading channel. The simulator emulates up to six DPDCH ${ }^{6}$ s and the DPCCH${ }^{7}$. However here the common physical channels (such as the Random Access Channel and the Physical Common Packet Channel) and the channel coding (specified in ETSI TS 125.212) are not modelled. The simulator output is an error length sequence. The error length sequence contains information about the number of consecutive symbols that were received errorfree and the number of consecutive symbols that were erroneously received.

\subsection{Simulation of Propagation conditions}

The standards proposed in [8] and [9] by the 3 GPP for radio transmission and reception was utilized for the simulation and there are number of different multipath channel propagation conditions for which the proposed methodology could be simulated as follows:

Table I: Propagation Conditions

\begin{tabular}{|c|c|c|c|c|c|}
\hline \multicolumn{2}{|c|}{$\begin{array}{c}\text { Case } 1 \\
\text { Speed } 3 \mathrm{~km} / \mathrm{h}\end{array}$} & \multicolumn{2}{|c|}{$\begin{array}{c}\text { Case } 2 \\
\text { Speed } 3 \mathbf{k m} / \mathbf{h}\end{array}$} & \multicolumn{2}{|c|}{$\begin{array}{c}\text { Case } 3 \\
\text { Speed } 120 \mathbf{k m} / \mathbf{h}\end{array}$} \\
\hline $\begin{array}{c}\text { Relative } \\
\text { delay } \\
(\mathrm{ns})\end{array}$ & $\begin{array}{c}\text { Average } \\
\text { Power } \\
(\mathrm{dB})\end{array}$ & $\begin{array}{c}\text { Relative } \\
\text { delay } \\
(\mathrm{ns})\end{array}$ & $\begin{array}{c}\text { Average } \\
\text { Power } \\
(\mathrm{dB})\end{array}$ & $\begin{array}{c}\text { Relative } \\
\text { delay } \\
\text { (ns) }\end{array}$ & $\begin{array}{c}\text { Average } \\
\text { Power } \\
(\mathrm{dB})\end{array}$ \\
\hline 0 & 0 & - & - & 0 & 0 \\
\hline 976 & -10 & 976 & 0 & 260 & -3 \\
\hline
\end{tabular}

Further data from publications of 3GPP [10], speed data given in website of Insurance Institute for Highway Safety, Highway Loss Data Institute, USA [11] and data from WINNER propagation scenarios [12] for urban macro-cell and micro-cell, stationary feeder, suburban macro-cell, and rural macro-cell were also considered in determining propagation conditions used for the simulation.

\section{Results and Analysis}

6.1 Results obtained for specific cases defined in 3GPP and WINNER propagation conditions.

6. Dedicated Physical Data Channels.

7. Dedicated Physical Control Channel.

8. 3GPP Case No (Refer Para 5.3).

9. WINNER Case Number.
It can be well observed from the first table below that the first row of the table provides maximum values of log likelihood for all bit lengths of the network trace obtained from a mobile station (which was moving at $3 \mathrm{kmh}$ ), confirming that the mobile is at the state of moving at a speed of $3 \mathrm{kmh}$.

Table 2: Results obtained for case- $\mathbf{1}^{8}$ at a speed of 3 $\mathbf{k m h}$ with an average power of $-10 \mathrm{db}$ error sequence

\begin{tabular}{|c|c|c|c|c|c|c|c|c|}
\hline \multirow{3}{*}{ 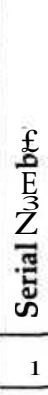 } & \multicolumn{5}{|c|}{ Test Conditions } & \multirow{2}{*}{\multicolumn{3}{|c|}{$\begin{array}{l}\text { Number of } \\
\text { characters under test } \\
\text { from a network trace } \\
\text { under conditions: } \\
\text { Case-1, } 3 \text { kmh Speed, } \\
\text { 10-Average Power- } \\
\text { ErrorSequence }\end{array}$}} \\
\hline & \multirow{2}{*}{ 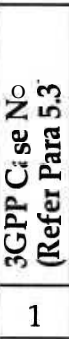 } & \multirow{2}{*}{$\begin{array}{l}\text { हूँ } \\
\text { हूँ } \\
\text { कूँ } \\
\text { के } \\
3\end{array}$} & \multirow[t]{2}{*}{ 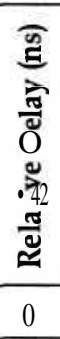 } & \multirow[t]{2}{*}{ 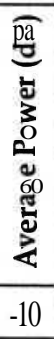 } & \multirow[t]{2}{*}{ 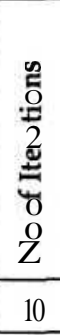 } & & & \\
\hline & & & & & & 43.3763 & -17.3894 & -14.4553 \\
\hline 2 & 1 & 3 & 0 & 0 & 10 & -66.7720 & -30.4749 & -21.1554 \\
\hline 3 & 3 & 120 & 0 & -3 & 10 & 45.2878 & -18.2927 & -15.0796 \\
\hline 4 & 4 & 250 & 0 & -3 & 10 & 44.8918 & -18.4940 & -14.8963 \\
\hline 5 & $\begin{array}{l}\text { Diffe } \\
\& \text { ne }\end{array}$ & $\begin{array}{l}\text { rence } \\
\text { xt lars }\end{array}$ & & & & 1.5155 & 0.9033 & 0.441 \\
\hline 6 & $\begin{array}{l}\text { Error } \\
\text { corre } \\
\text { value }\end{array}$ & $\begin{array}{l}\text {-Diffe } \\
\text { ct valı }\end{array}$ & & & & 0.0000 & 0.0000 & 0.0000 \\
\hline
\end{tabular}

Table 3: Results obtained for Case-C1 Metropol', at a speed of $70 \mathrm{kmh}$ with an Average Power of $-10 \mathrm{~dB}$ Error Sequence

\begin{tabular}{|c|c|c|c|c|c|c|c|c|}
\hline \multirow{3}{*}{ 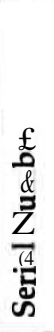 } & \multicolumn{5}{|c|}{ Test Conditions } & \multirow{2}{*}{\multicolumn{3}{|c|}{$\begin{array}{l}\text { Number of characters } \\
\text { under test from a } \\
\text { network trace under } \\
\text { conditions: Case-70 } \\
\text { kmh Speed, 10- } \\
\text { Average Power-Error } \\
\text { Sequence }\end{array}$}} \\
\hline & \multirow{2}{*}{ 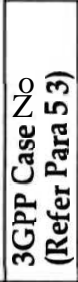 } & \multirow{2}{*}{ 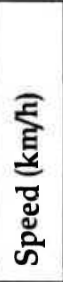 } & \multirow{2}{*}{ 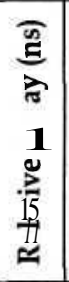 } & \multirow{2}{*}{ 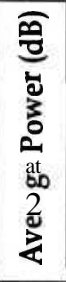 } & \multirow{2}{*}{ 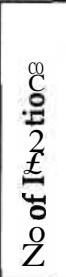 } & & & \\
\hline & & & & & & 143 & 100 & 50 \\
\hline 1 & 1 & 3 & 0 & -10 & 10 & 41.8142 & -29.4134 & -15.1109 \\
\hline 2 & 1 & 3 & 0 & 0 & 10 & -61.7223 & 43.7125 & -23.2320 \\
\hline 3 & 3 & 120 & 0 & -3 & 10 & 42.2476 & -29.7515 & -15.5786 \\
\hline 4 & - & 70 & 0 & -10 & 10 & 41.5157 & -29.1497 & -14.8457 \\
\hline 5 & $\begin{array}{l}\text { Diffe } \\
\& \text { ne }\end{array}$ & larg & & arges & & 0.2985 & 0.2637 & 0.2652 \\
\hline 6 & $\begin{array}{l}\text { Error } \\
\text { corre } \\
\text { value }\end{array}$ & -Diffe & & $\begin{array}{l}\text { veen } \\
\text { st }\end{array}$ & & 0.0000 & 0.0000 & 0.0000 \\
\hline
\end{tabular}

Here the fourth row provides maximum values of log likelihood for all most all the bit lengths of a network trace obtained from a mobile station (which was moving at 70 $\mathrm{kmh}$ ),confirming that the mobile is at the state moving at a speed of $70 \mathrm{kmh}$. 
Table 4: Results obtained for Case- $3^{10}$, at a speed of $120 \mathrm{kmh}$ with an Average Power of-3dB Error Sequence

\begin{tabular}{|c|c|c|c|c|c|c|c|c|}
\hline \multirow{3}{*}{ 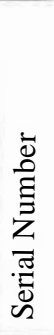 } & \multicolumn{5}{|c|}{ Test Conditions } & \multirow{2}{*}{\multicolumn{3}{|c|}{$\begin{array}{l}\text { Number of characters } \\
\text { under test from a } \\
\text { network trace under } \\
\text { conditions: Case-3, } \\
\text { 120kmh Speed, 3- } \\
\text { Average Power- Error } \\
\text { Sequence }\end{array}$}} \\
\hline & \multirow{2}{*}{ 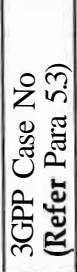 } & \multirow{2}{*}{ 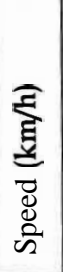 } & \multirow{2}{*}{ 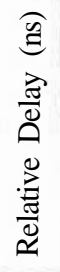 } & \multirow{2}{*}{ 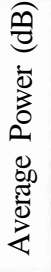 } & \multirow{2}{*}{ 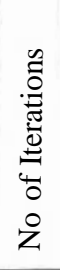 } & & & \\
\hline & & & & & & 143 & 100 & an \\
\hline 1 & 1 & 3 & $\theta$ & -18 & 10 & $-32,2175$ & -21.9917 & -11.2551 \\
\hline 2 & 1 & 3 & 8 & $\theta$ & 10 & $-31,058$ & -20.0595 & $-10 \cdot-1$ \\
\hline 3 & 8 & 120 & 0 & -3 & 18 & -29.5782 & -19.8389 & $-10.0 / 2$ \\
\hline 4 & 4 & 6 & 8 & -3 & 10 & -38.6771 & -20.561 & -10.315 \\
\hline 5 & $\begin{array}{l}\text { Tiffe } \\
\& m e\end{array}$ & $\mathrm{xt}$ & & & & 1.0989 & 8.2206 & 0.5 oD \\
\hline 6 & $\begin{array}{l}\text { Error } \\
\text { corre } \\
\text { value }\end{array}$ & $\begin{array}{l}\text {-Differ } \\
\text { ct valu }\end{array}$ & & & & 8.0000 & 8.0000 & 0.0000 \\
\hline
\end{tabular}

Finally the th $\boldsymbol{w}$ row provides maximum values of $\log$ likelih for all the bit lengths obtained from a mobile station (which was moving at 20

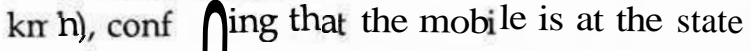
of moving ha speed of $120 \mathrm{kmh}$.

\subsection{R esults obtain $d$ at interricsdiate speeds to check the cliability of propposed onethod.}

The speeds utilized to obtain the network traces were focused around two speed loels manely $70 \mathrm{kmh}$ and $120 \mathrm{kmh}$ for $\mathrm{gnitiph}^{\mathrm{h}}$ th propo $\equiv \mathrm{d}$ m. thod provided best reco on of us@r state.

The objective of this endeavour was to ascertain how best the proposed method can recognize plus or minus speeds around a certain value, on which the hidden markov model (with which we try to recognize the speed level) is based upon. For this test speed levels $60 \mathrm{kmh}, 65 \mathrm{kmh}$ and $75 \mathrm{kmh}$ were used around the $70 \mathrm{kmh}$ speed level and $100 \mathrm{kmh}, 110 \mathrm{kmh}, 125 \mathrm{kmh}$ and 130 $\mathrm{kmh}$ were used around the $120 \mathrm{kmh}$ speed level.
Table 5 : Results obtained at a speed of $60 \mathrm{kmh}$ with an Average Power of -10 dB Error Sequence.

\begin{tabular}{|c|c|c|c|c|c|c|}
\hline \multirow{3}{*}{ 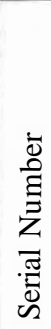 } & \multicolumn{5}{|c|}{ Test Conditions } & \multirow[b]{2}{*}{$\begin{array}{c}\text { Number of } \\
\text { characters under test } \\
\text { from Case-x, } 60 \mathrm{kmh} \\
\text { Speed, -10-Average } \\
\text { Power- Error } \\
\text { Sequence }\end{array}$} \\
\hline & \multirow{2}{*}{ 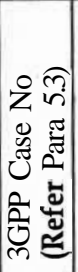 } & \multirow{2}{*}{ 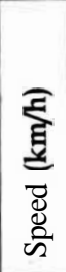 } & \multirow[t]{2}{*}{ 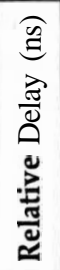 } & \multirow[t]{2}{*}{ 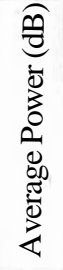 } & \multirow{2}{*}{ 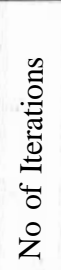 } & \\
\hline & & & & & & 120 \\
\hline 1 & 1 & 3 & 0 & -10 & 10 & -33.7264 \\
\hline 2 & 1 & 8 & 0 & 0 & 10 & -47.4620 \\
\hline 3 & 3 & 120 & 0 & -3 & 10 & $-34.571 z$ \\
\hline 4 & - & $\boldsymbol{\omega}$ & 0 & -10 & 10 & $-33.490 \Omega$ \\
\hline 5 & \multicolumn{5}{|c|}{$\begin{array}{l}\text { Difference between largest } \\
\text { \& next largest value }\end{array}$} & 0.2278 \\
\hline$z$ & \multicolumn{5}{|c|}{$\begin{array}{l}\text { Error-Difference between } \\
\text { correct value \& largest } \\
\text { value }\end{array}$} & 0 \\
\hline
\end{tabular}

In this sase the four $n$ ro $_{\mathrm{w}}$ provides the maxior $\Omega \Omega$ value of log likelihood for 120 bit length obtained fror a mobile sta ion (wl ich was moving at $(1 \mathrm{kl}(\mathrm{h})$, recognizing th $\sigma$ the mobile if at the state of moving at the r $\mathcal{O S}_{s t}$ speed of $70 \mathrm{kmh}$.

Table 6: Results obtained at a speed of $65 \mathrm{kmh}$ with an Average Power of $0 \mathrm{~dB}$ Error Sequence.

\begin{tabular}{|c|c|c|c|c|c|c|}
\hline \multirow{3}{*}{ 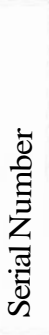 } & \multicolumn{5}{|c|}{ Test Conditions } & \multirow[b]{2}{*}{$\begin{array}{c}\text { Number of } \\
\text { characters under test } \\
\text { from Case-y, } 65 \mathrm{kmh} \\
\text { Speed, 0-Average } \\
\text { Power- Error } \\
\text { Sequence }\end{array}$} \\
\hline & \multirow{2}{*}{ 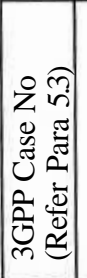 } & \multirow{2}{*}{ 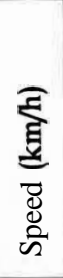 } & \multirow{2}{*}{ 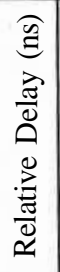 } & \multirow{2}{*}{ 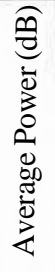 } & \multirow{2}{*}{ 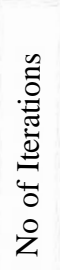 } & \\
\hline & & & & & & 120 \\
\hline 1 & 1 & 3 & 0 & -10 & 10 & $-3 z .6234$ \\
\hline 2 & 1 & 3 & 0 & 0 & 10 & $-56, z \infty_{1}$ \\
\hline 3 & 3 & 120 & 0 & -3 & 10 & -38.5652 \\
\hline 4 & - & 70 & 0 & -10 & 10 & $-3 z .22 z 2$ \\
\hline $\bar{\sigma}$ & \multicolumn{5}{|c|}{$\begin{array}{l}\text { ofif:erence between largest } \\
\infty \text { next largest value }\end{array}$} & 0.3972 \\
\hline 6 & \multicolumn{5}{|c|}{$\begin{array}{l}\text { Emor-Difference between } \\
\text { vorrect value \& largest } \\
\text { value }\end{array}$} & 0 \\
\hline
\end{tabular}

In this case the fourth row provides the maximum value of log likelihood for 120 bit length obtained from a mobile station (which was moving at $65 \mathrm{kmh}$ ), recognizing that the mobile is at the state of moving at the nearest speed of $70 \mathrm{kmh}$. 
Table 7 : Results obtains at a spe

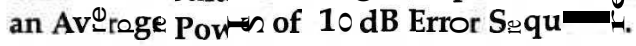

\begin{tabular}{|c|c|c|c|c|c|c|}
\hline \multirow{3}{*}{ 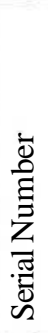 } & \multicolumn{5}{|c|}{ Test Conditions } & \multirow[b]{2}{*}{$\begin{array}{c}\text { Numbes of } \\
\text { =haracters \&order tes } \\
\text { f } \sim \mathrm{m} \text { Case-z, } 75 \mathrm{kmh} \\
\text { Speed, 10-Average } \\
\text { Power- Error } \\
\text { Sequence }\end{array}$} \\
\hline & \multirow[t]{2}{*}{ 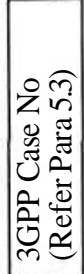 } & \multirow[t]{2}{*}{ 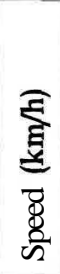 } & \multirow[t]{2}{*}{ 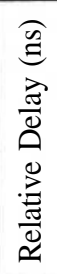 } & \multirow[t]{2}{*}{ 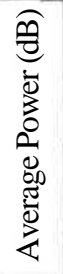 } & \multirow[t]{2}{*}{ 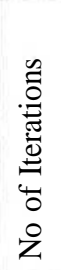 } & \\
\hline & & & & & & 120 \\
\hline 1 & 1 & 0 & 0 & -10 & 10 & -35 .ss \\
\hline 2 & 1 & 0 & 0 & 0 & 10 & -51.6111 \\
\hline 0 & 0 & 120 & 0 & -3 & 10 & 408 \\
\hline 4 & - & 70 & 0 & -10 & 10 & $-34,748 \leqslant$ \\
\hline 5 & \multicolumn{5}{|c|}{$\begin{array}{l}\text { Difference between largest } \\
\& \text { next largest value }\end{array}$} & 0.2929 \\
\hline 6 & \multicolumn{5}{|c|}{$\begin{array}{l}\text { Error-Difference between } \\
\text { correct value \& largest } \\
\text { value }\end{array}$} & 0 \\
\hline
\end{tabular}

In this cacs the foorn row provid $\cdot \bullet^{\circ}$ maximu $_{n}$ value of $\log$ likelihood for $C_{2}$ bit length ot tained fro $f \hat{a}$ a bobile station ich was mov' $\bar{O}$ at $75 \mathrm{k}(\mathrm{Sh})$, recognizing that the mobile is at the state of moving at the nearest $\mathrm{sp} \times \mathrm{ed}$ of $70 \mathrm{kmh}$.

Tabl

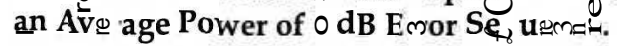

\begin{tabular}{|c|c|c|c|c|c|c|}
\hline \multirow{3}{*}{ 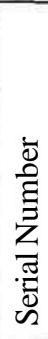 } & \multicolumn{5}{|c|}{ Test Conditions } & \multirow[b]{2}{*}{ 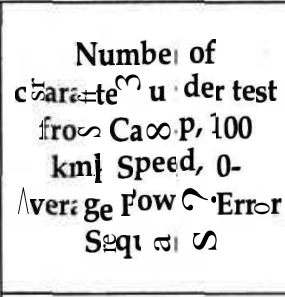 } \\
\hline & \multirow{2}{*}{ 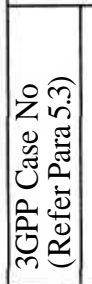 } & \multirow{2}{*}{ 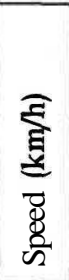 } & \multirow[t]{2}{*}{ 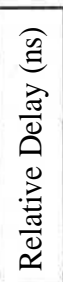 } & \multirow[t]{2}{*}{ 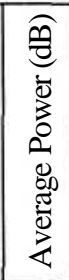 } & \multirow[t]{2}{*}{ 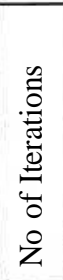 } & \\
\hline & & & & & & 120 \\
\hline 1 & 1 & 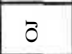 & 0 & -10 & 10 & -23.1550 \\
\hline$?$ & 1 & 3 & 0 & 0 & 10 & .13 .7291 \\
\hline 0 & 3 & 120 & 0 & -3 & 10 & -18. \\
\hline 4 & - & 70 & 0 & -10 & 10 & -23.5905 \\
\hline 5 & \multicolumn{5}{|c|}{$\begin{array}{l}\text { تifference üetunom argest } \\
\text { \& Mext largest valu \& }\end{array}$} & 4.524 \\
\hline 6 & \multicolumn{5}{|c|}{$\begin{array}{l}\text { Er on Nff rence etweem } \\
\text { s)rr o valus \& large t } \\
\text { value }\end{array}$} & 4.524 \\
\hline
\end{tabular}

In th s case the secos raw prides the $3_{x} \times$ ir num value of $\log \mathrm{ji}_{\mathrm{k}}$ elth ${ }^{\sigma}$ for $120 \mathrm{bit}$ lemgtl obtained $\mathrm{f} M \mathrm{M}$ a lobile station (which

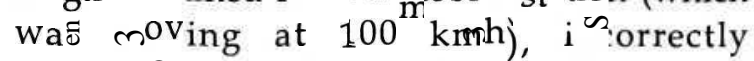
reoog riz. -5 that the - bile $1 s^{t}$ the state of moving at the nearest spee, $0 \mathrm{fO}^{\circ} \mathrm{kml}$.
Table 9: Results obtained at a speed of $110 \mathrm{kmh}$ with an Average Power of $0 \mathrm{~dB}$ Error Sequence.

\begin{tabular}{|c|c|c|c|c|c|c|}
\hline \multirow{3}{*}{ 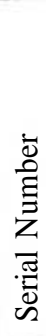 } & \multicolumn{5}{|c|}{ Test Conzitions } & \multirow[b]{2}{*}{ 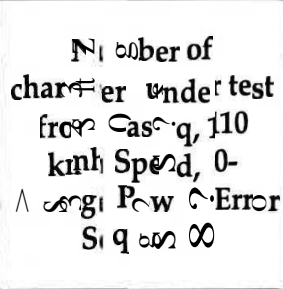 } \\
\hline & \multirow{2}{*}{ 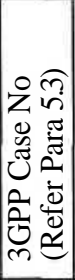 } & \multirow{2}{*}{ 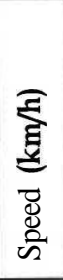 } & \multirow[t]{2}{*}{ 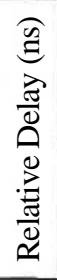 } & \multirow[t]{2}{*}{ 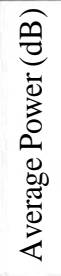 } & \multirow[t]{2}{*}{ 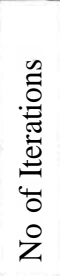 } & \\
\hline & & & & & & 120 \\
\hline 1 & 1 & 0 & 0 & -10 & 10 & -29.8890 \\
\hline $\bar{z}$ & 1 & 0 & 0 & 0 & 10 & -05.1058 \\
\hline 3 & 0 & $=20$ & 0 & -3 & 10 & $-29.1 \leqq 94$ \\
\hline$\dot{\hat{\theta}}$ & - & 70 & 0 & -10 & 10 & -29 . 쟈 81 \\
\hline 5 & \multicolumn{5}{|c|}{$\begin{array}{l}\text { Oiffe mog between lar } \\
\infty \text { M } \times 1 \text { larges value } \\
\infty\end{array}$} & 0.7087 \\
\hline \% & \multicolumn{5}{|c|}{$\begin{array}{l}\text { Ermn cffusnce betwesn } \\
\text { •rr = va us \& argest } \\
\text { va ue }\end{array}$} & 0 \\
\hline
\end{tabular}

In this case the thire row provides the 1 -ximum value of $\log$ likelihood for 120 ơit length btained from a mobile station (which was roving at $100 \mathrm{kmh}$ ), recognizing that the mobile is at the state of moving at $t h$ ? neərest spoed of $120 \mathrm{kmh}$.

Table 10: Rasuts $\circ \mathrm{b}$ ain $\mathrm{d}$ at a speed of $125 \mathrm{kmh}$ with an Averdfe $\mathrm{P} c \mathrm{C}$ c of $\mathbf{- 3} \mathrm{dB}$ wiror Sequence.

\begin{tabular}{|c|c|c|c|c|c|c|}
\hline \multirow{3}{*}{ 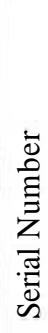 } & \multicolumn{5}{|c|}{ Test Conditions } & \multirow[b]{2}{*}{$\begin{array}{c}\text { Number of } \\
\text { characters under test } \\
\text { from Case-r, } 125 \mathrm{kmh} \\
\text { Speed, 3-Average } \\
\text { Power- Error } \\
\text { Sequence }\end{array}$} \\
\hline & \multirow{2}{*}{ 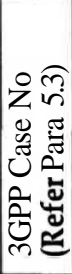 } & \multirow{2}{*}{ 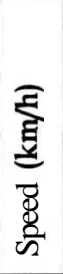 } & \multirow[t]{2}{*}{ 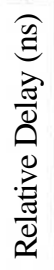 } & \multirow[t]{2}{*}{ 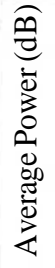 } & \multirow{2}{*}{ 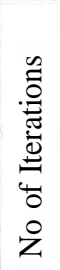 } & \\
\hline & & & & & & 120 \\
\hline 1 & 1 & 0 & 0 & -10 & 10 & $-30,8249$ \\
\hline 2 & 1 & 0 & 0 & 0 & 10 & ת \\
\hline o & o & 120 & 0 & -3 & 10 & -30.2924 \\
\hline 4 & - & 70 & 0 & -10 & 10 & -30.7446 \\
\hline 5 & \multicolumn{5}{|c|}{$\begin{array}{l}\text { Difference between largest } \\
\& \text { next largest value }\end{array}$} & 0.4522 \\
\hline z & \multicolumn{5}{|c|}{$\begin{array}{l}\text { Error-Difference between } \\
\text { correct value \& largest } \\
\text { value }\end{array}$} & 0 \\
\hline
\end{tabular}

In tlis mse the third row provides the ma×imnm value of log likelihcou for 120 bit length Obtained from a mobile wrs $\mathrm{mN}$ ing at $125 \mathrm{kmh}$ ), recog izing that the

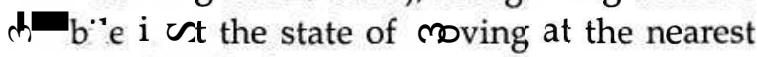
speed of $120 \mathrm{kmh}$. 
Table 11 : Results obtained at a speed of $130 \mathrm{kmh}$ with an Average Power of $0 \mathrm{~dB}$ Error Sequence.

\begin{tabular}{|c|c|c|c|c|c|c|}
\hline \multirow{3}{*}{ 㐫 } & \multicolumn{5}{|c|}{ Test Conditions } & \multirow[b]{2}{*}{$\begin{array}{c}\text { Number of } \\
\text { characters under test } \\
\text { from Case-s, } 130 \mathrm{kmh} \\
\text { Speed, 0-Average } \\
\text { Power- Error } \\
\text { Sequence }\end{array}$} \\
\hline & \multirow{2}{*}{ 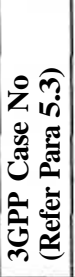 } & \multirow{2}{*}{ 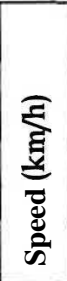 } & \multirow[t]{2}{*}{ 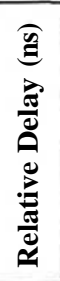 } & \multirow[t]{2}{*}{ 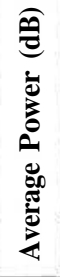 } & \multirow{2}{*}{ 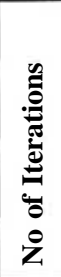 } & \\
\hline & & & & & & 120 \\
\hline 1 & 1 & 3 & $\mathbf{0}$ & -10 & 10 & -31.7836 \\
\hline 2 & 1 & 3 & $\mathbf{0}$ & $\mathbf{0}$ & 10 & -41.2973 \\
\hline 3 & 3 & 120 & $\mathbf{0}$ & -3 & 10 & -31.7304 \\
\hline 4 & - & 70 & $\mathbf{0}$ & -10 & 10 & -31.6484 \\
\hline 5 & \multicolumn{5}{|c|}{$\begin{array}{l}\text { Difference between largest } \\
\text { \& next largest value }\end{array}$} & 0.082 \\
\hline 6 & \multicolumn{5}{|c|}{$\begin{array}{l}\text { Error-Difference between } \\
\text { correct value } \& \text { largest } \\
\text { value }\end{array}$} & 0.082 \\
\hline
\end{tabular}

Finally here the fourth row provides the maximum value of log likelihood for 120 bit length obtained from a mobile station (which was moving at $130 \mathrm{kmh}$ ), incorrectly recognizing that the mobile is at the state of moving at the nearest speed of $70 \mathrm{kmh}$.

\section{Conclusions}

\subsection{Summary}

The results indicate that the proposed method is able to assist to create a meaningful user context model for the selection of the characteristics of Location Based Services, at various propagation conditions defined by both 3GPP and WINNER propagation scenarios (up to a maximum speed of $120 \mathrm{kmh}$ ) as a passive method only requiring a network trace, and without an integrated sensor onboard cellular phone or any other wearable sensor device, that is: with less modifications to the all applicable mobile transceivers to WCDMA.

\subsection{Evaluation}

The selected statistical HMM models are generally very rich in mathematical structure and hence can form the theoretical basis for use in a wider range of applications. The method of maximum likelihood provided estimators that have both a reasonable intuitive basis and many desirable statistical properties. The main reason for the selection of maximum likelihood method is that it is very broadly applicable and simple to apply. Identification of the state was simple as: computation of log likelihood of the data for each hidden markov model in the set and identify the state by choosing the hidden markov model that produced the highest value without utilization of complex algorithms such as Viterbi, hence significantly faster and lesser burden on processing.

For the verification of proposed method the WCDMAsim $^{\mathrm{TM}}$ was utilized as the simulator of physical layer of $3 \mathrm{G}$ wireless system developed by Mobile and Portable Radio Research Group at, Virginia Polytechnic Institute and State University, Blacksburg, Virginia, which provided a technically accurate and detailed emulation of a WCDMA system.

One unique feature of WCDMAsim is its ability to produce more than just average BER ${ }^{11}$ statistics. Rather, this simulator provides users with an error length sequence that contains not only the number of errors but also the location of each error in the data sequence. This information is crucial for the development of computationally efficient simulations, such as Hidden Markov Model simulations of largescale wireless networks [30].

The proposed method found to advantageous in view of that it eliminates integrated sensor on cellular phone and hence minimum modification to the existing of future WCDMA compatible mobile phones.

Further the proposed method eliminates any sort of signalling of data on the user state from Mobile station to base station or vice versa, since the proposed method is a one way passive process of analysing a received network trace.

Generally for state recognition methods based on channel estimation methods: faster the mobile station is, shorter the optimum pilot length for channel estimation will be, due to the difficulty in tracking faster channel variations, hence lesser accuracy. This minus point will become a plus point for the proposed method, since it is taken number of error symbols with compared to number correct bits into account during recognition of user state.

11. Bit Error Rate. 
Further to above higher the mobile station speed, more frequently the signal fades, again the proposed method gains the advantage as explained above.

Even though the proposed model was tested in WCDMAenvironmentfor standard scenarios in order to check it's ruggedness, it could be well applied to other cellular technologies and also can be customized to recognize any user state: as Still, Walking, Brisk walk, Cycling, Highway Driving, Rural Driving etc, say in order to direct the correct type of advertisements to the user mobile transceiver or PSAP ${ }^{12}$ to distributes the emergency call to the proper type of services; for example to the nearest Police post or to Police mobile vehicle.

The automatic or unsupervised initiation of the process could be performed by sensing the change of Cell ID or could be incorporated to any other mobile location method utilized.

Jeffrey $\mathrm{H}$. Reed et al [13] have recognized first major challenge as radio frequency channel imperfections particularly multipath time dispersion and interference. The proposed method prevents most of problems caused by NLOS and multipath propagation (which is already taken into account in the network trace), where as the accuracy of channel estimation methods, dependent upon the measurements, degradesignificantly.

Finally a large amount of data was involved in analysing the output of the WCDMA simulator and consequent conversion of same to a bit train of ' 1 's and 'O's, which was the input to the building of hidden markov models: that is improvement of initial model parameters as explained in above paragraph 4.1. It could have been better if any data clustering method such as K-means or Principle Component Analysis was utilized in order to extract significant components of data.

\subsection{Applications}

The process based on proposed method could be a part of organization of services and a single service interface that provides applications with contextual information. Such a system is proposed by Glenn Judd and Peter Steenkiste in [14] which introduces a concise organization of services and a single service interface that provide applications with contextual information in a unified manner and shows, via example applications and services that have been implemented, how the proposed service organization and interface can be used to allow proactive applications to adapt their behaviour to match a user's current environment.

V Bellocci et al [15] identify location-based services: News, Traffic Information, Yellow Pages Services and Fleet Management are as services that require low level of accuracy. For such types of services, utilization of a complex and expensive method to determine user behaviour is not worth and the proposed method is expected to be worthwhile for implementation for such services due to its simplicity and comparatively low cost compared to hardware based systems. Juha Korhonen [16, p474], emphasizes the importance of cost criteria in the selection of a service by a future $4 \mathrm{G}$ user (or rather a smart device) as, "The smart device can analyze its environment and choose the best available service provider and technology (service discovery). The evaluation is based not only on radio path characteristics, as in current networks, but on other parameters, such as QoS $^{13}$, cost, and security', unquote.

Monitoring the speed in passive mode of a particular mobile user, would be very convenient for law enforcement agencies as there would be no need for special speed radars as well as it may also be used to activate a camera which is in sleeping mode, or they could send an instant speeding ticket via 3G device.

Finally even though the speed of the user was selected as the parameter of recognition, the same method may be utilized to recognize a user by utilization of any of the other appropriate parameters.

12. Public Safety Answering Point - A dispatch office that receives 911 calls from the public.

13. Quality of Service - 3GPP Release 5 specifications of June 2002 : TS 23.107 defines Quality of Service (QOS) Concept and Architecture. 


\section{Future Work}

The computational burden associated with the Baum-Welch algorithm is quite higher for longer error vectors, since the forward and backward variables are computed for each symbol and convergence is observed to be slower. Sivaprakasam and Shanmugan [17] have showed that under some assumptions, a markov model with an arbitrary transition matrix is equivalent to a markov model with a unique block diagonal transition matrix and presented a computationally efficient algorithm, for estimation of transition matrix from a set of observations, called modified Baum-Welch algorithm. However they have shown that the particular algorithm is computationally efficient when the overall bit error rate for the source is small and the error sequence contains long stretches of identical symbols [17]. The utilization of modified Baum-Welch algorithm might accelerate the real time execution of proposed methodology.

Further to above the conclusions by Andrea $\mathbf{J}$. Goldsmith and Larry J. Greenstein in [18] states that the short term fluctuation statistics of signal attenuation, for LOS(NLOS) regions of a microcell are Rice-like(Rayleigh-like), may be utilized as priori information in further improvement of the proposed method. For example generation of markov model parameters such as initial state matrix could be based on either of Rice-like(Rayleigh-like), models as per the situation.

Finally let us conclude quoting $\mathrm{K}$ W Richardson [19], who states: 'the range of $3 \mathrm{G}$ services will truly only be limited by the imagination of the service provider', unquote.

\section{Acknowledgement}

The authors owe a debt of gratitude to, Professor RMP Rajatheva of AIT, Thailand and Dr RP Thilakumara of UOM, for assisting in finding of required research papers, and for all researchers and authors for the stimulating ideas gained from their work listed in the references.

\section{References}

1. http://www.mobilein.com.

2. SnapTrack, A Qualcomm Company, Location Technologiesfor GSM, GPRS and UMTS Networks, 2003.

3. Trond Nypan, and Oddvar Hallingstad, A cellular positioning system based on database comparison The hidden Markov model based estimator versus the Kalmanfilter, Unik-University Graduate Centre, Norway.

4. Daniel Siewiorek, Asim Smailagic, Junichi Furukawa,NeemaMoraveji, KathrynReiger, and Jeremy Shaffer, SenSay: A Context-Aware Mobile Phone, Human Computer Interaction Institute and Institute for Complex Engineered Systems, Carnegie Mellon University.

5. Andreas Krause, Asim Smailagic, and Daniel P. Siewiorek, Context-Aware Mobile Computing: Learning Context-Dependent Personal Preferences from a Wearable Sensor Array, IEEE TRANSACTIONS ON MOBILE COMPUTING, VOL. 5, NO. 2, FEBRUARY 2006.

6. Ian Anderson, Henk Muller, Practical Activity Recognition Using GSM Data, Department of Computer Science, University of Bristol, UK.

7. The WCDMASimulator User's Manual, Virginia Polytechnic Institute and State University, Virginia, 2002.

8. 3GPP TS 25.104, BS Radio Transmission and Reception(FDD), Technical specification group radio access networks, Release 2003 v4.7.0, 3rd Generation Partnership Program.

9. 3GPP Website: http://www.3GPP.org.

10. 3GPP, 'Deleting Physical Channel BER measurement from TS 25.215', http:// www.3gpp.org/ftp/tsg_ran/WG1_RL1/ TSGR1_09/Docs/PDFs/Rl-99j17.pdf, December 1999.

11. Insurance Institute for Highway Safety, Highway Loss Data Institute Website: http:// www.iihs.org/laws/state_law s/ speed_limit_laws.html.

12. Daniel S. Baum, Hassan El-Sallabi, Tommi Jämsä, Juha Meinila, Pekka,Kyb'sti, Xiongwen Zhao, Daniela Laselva, Jukka-Pekka, Nuutinen, Lassi, Hentilä, Pertti Vainikainen, Jarmo Kivinen, Lasse Vuokko, Per Zetterberg, Mats Bengtsson, Kai Yu, Niklas Jaldén, Terhi Rautiainen, Kimmo Kalliola, Marko Milojevic, Christian Schneider, Jan Hansen, Final Report on Link Level and System Level Channelmodels, IST-2003-507581 WINNER D5.4 v. 1.4, Wireless World Initiative New Radio, November 2005. 
13. Jeffrey H. Reed, Kevin J. Krizman, Brian D. Woerner, and Theodore S. Rappaport, An Overview of the Challenges and Progress in Meeting the E - 911 Requirementfor Location Service, IEEE Communications Magazine, April 1998.

14. Glenn Judd and Peter Steenkiste, 'Providing Contextual Information to Ubiquitous Computing Applications', School of Computer Science, Carnegie Mellon University, Pittsburgh, July 2002.

14. V Bellocci, S Genovese, D Inuaggiato, and M Tucci, Mobile Location-Aware Services: 2002 Market Perspective, Ericsson, Division Service Architecture and Interactive Solutions, July 2002.

16. Juha Korhonen, Introduction to $3 G$ Mobile Communications', Second Edition, Artech House, Boston, 2003.

17. Sirinivas Sivaprakasam and K Sam Shanmugan, An equivalent Markov Modelfor Burst Errors in Digital Channels, IEEE Transactions on Communications, Vol 43, No 2/3/4, February/ March/April 1995.

18. Andrea J. Goldsmith and Larry J. Greenstein, $A$ Measurement - Based Model for Predicting Coverage Areas of Urban Microcells, IEEE JOURNAL ON SELECTED AREAS IN COMMUNICATIONS, VOL 11, NO 7, September 1993.

19. K W Richardson, UMTS overview, Electronic \& Communication in Engineering Journal, June 2000 